\title{
The Research of Practic-oriented Talent Cultivation Pattern for Automobile Service Engineering Specialty
}

\author{
ZHONG Yu-hua ${ }^{1}$, SUN Guo-hui ${ }^{2}$ \\ ${ }^{1)}$ Guangzhou College of South China University of Technology, Guangzhou 510800, P.R. China (ayhua.zhong@gmail.com) \\ ${ }^{2)}$ China Construction First Building (Group) Corporation Limited, Shenzhen518000, P.R. China (b457219202@qq.com)
}

\begin{abstract}
With the development of China's automobile industry, the automobile industry rapid development has brought great students living space, forms the sharp contrast with this is China's automobile talent shortage. At present, talent shortage has seriously restricted the development of China's automobile industry, talent has become the bottleneck to the development of automobile industry. The development of automobile industry not only needs to be able to Chinese $R \& D$ technology leader in design, senior technicians, technicians need to understand the production and repair, also need technical service personnel for the automotive after market. According to the characteristics of Applied Talents Cultivation of the independent college, the innovative talents training mode of exploration.
\end{abstract}

Keywords - Independent College, application, automotive service, personnel training

\section{独立学院汽车服务工程专业应用型人才培养模式改革 研究}

\author{
钟玉华 ${ }^{1}$ 孙国辉 $^{2}$ \\ 1) 华南理工大学广州学院汽车工程学院, 广州, 中国 \\ 2) 中国建筑一局（集团）有限公司，深圳，中国
}

\begin{abstract}
摘 要 随着我国汽车行业的发展, 汽车产业蓬勃发展带来了巨大生的存空间, 与此形成鲜明对比的是我国汽车人才的匮乏状况。 当前, 人才匮乏已严重制约了我国汽车产业的发展, 人才问题已经成为发展汽车产业的瓶颈。中国汽车产业的发展既需要能够进行研 发设计的技术带头人, 又需要懂得生产和维修的高级技工、技师, 还需要汽车后市场的技术服务人才。文章针对独立学院应用型人才 培养的特点, 对汽车服务工程专业创新人才培养模式进行探索研究。
\end{abstract}

关键词 独立学院; 应用型; 汽车服务; 人才培养

1. 引言

随着汽车业的迅猛发展, 汽车的科技含量不断提高。 汽车产业的飞速发展带动了汽车维修技术的进步, 维修设 备现代化、维修资讯网络化、维修诊断专家化、维修管理 电脑化已成趋势; 在进口车大量进入国内的同时, 国外汽 车维修企业、汽车保险、汽车金融、配件等也将以汽车服 务贸易的形式进入国内市场，新观念、新技术、新工艺、 现代化的管理手段和管理机制也逐步引入国内汽车服务企 业。汽车服务业随之发展成为一个独立的、具有极大发展 空间和潜力且要求越来越高的技术服务性行业, 对从业人
员特别是技术人员提出了较高的专业要求。目前, 许多高 校, 特别是应用型本科院校纷纷开设了汽车服务工程专业。 随着我国加入 WTO 和经济全球化的发展, 汽车检测与维修 人才短缺问题日显突出。据调研显示, 随着汽车保有量的 大幅度上升, 全国汽车维修行业每年需要新增近 30 万从业 人员。因此, 汽车检测与维修技术专业的人才培养被优先 列入 “国家制造业和现代服务业技能型紧缺人才培养培训 工程”。

\section{2. 研究意义}

广东是我国的汽车后市场消费大省 ${ }^{[1]}$, 据交通管理部门 
统计： 2006 年 1 月至 10 月, 广州平均每月上牌的汽车达 1 万 1 千多台, 11 月达 1 万 7 千多台, 2006 年全年销售量超 过 150 万辆, 汽车后市场产业具有很大的发展空间。但我 国目前具备专业理论知识和掌握操作技能的汽车高级维 修、理赔人才却相当紧缺。汽车运用与维修专业人才已被 国家教育部定为第一批急需和紧缺人才, 以广州为中心的 广东省经济发达, 汽车拥有量大, 对汽车检测与维修人才 的需求更为迫切, 缺口很大。特别是具有高级工以上的可 以独挡一面的人才紧缺。市场紧缺汽车检测与维修技术人 才。企业要求这些人员不仅应有一定的基础理论和专业知 识, 而且还应具有较强的实际技能。因此, 培养汽车服务 工程专业应用型人才, 对学院、对企业、对社会对广东省 的汽车行业的发展都具有十分重要的意义。

\section{3. 改革实施方案}

为了解决我国汽车领域出现的技能型人才严重短缺的 情况, 结合我省实际问题, 汽车工程学院借鉴国外先进经 验, 在汽车服务工程专业应用型人才的培养模式上尝试改 革, 实现新的突破。具体实施方案主要以下五个方面开展:

\section{1 以市场需求为导向, 优化专业结构}

现代教育最大的特点就是人才培养与社会发展需求相 吻合甚至超前。汽车尤其是汽车服务相关产业呈现出来的 对人才的渴求是教育部门的基本着眼点。适应社会需求, 最直接的途径就是对专业结构进行优化组合。汽车维修技 术、汽车运用技术、汽车销售业务管理、汽车保险业务管 理、旧车评估技术、企业经营管理、事故鉴定与理赔技术、 汽车检测技术等专业都是社会需求的热点, 也是专业改革 的发展方向。汽车服务工程专业密切贴近人才市场, 通过 自我调控, 逐步建立起弹性化、多样化、个性化的专业培 养模式。

\section{2 改革培训课程与教学方法}

培训课程是培养目标的具体化, 是人才培养模式改革 的主要落脚点。培养应用型的汽车服务工程专业人才, 重 点就是实践能力的培养, 目前, 我国不少高校的汽车专业 仍然使用 20 世纪 70-80 年代的教材, 学的还是中型货车的 发动机结构, 学生的实践机会也很少。相比而言, 发达国 家汽车专业培训大都由各大汽车公司和高校联合进行, 属 于定向培训, 学生有一半的时间在生产线上实习, 对专业 非常熟悉。所以新型汽车服务工程专业人才的培养离不开 课程与教学方法改革。优化培训课程结构应以提高技术型 专业人才应用能力为目标, 积极开展教育教学改革, 逐步 形成与现代汽车服务工程应用型人才要求相适应的人才培
养体系, 包括人才培养模式、课程体系、精品课程、精品 教材、教学软件和实践教学基地等。还应以应用为主旨和 特征, 构建相互独立又紧密联系的课程教学体系。通过这 些改革, 使课程体系中的理论与实践环节成为有机统一的 整体, 体现培训课程体系的科学性、特色性及可操作性。

\section{3 加强实践性教学}

加强实践教学是一个很重要环节。在汽车服务工程专 业课程的学习过程中, 学生对各种汽车检测设备的熟练使 用、汽车故障诊断方法的掌握都要依靠实践教学。学生对 汽车知识的学习, 仅靠传统的挂图、教材讲解是无法完成 的。要运用现代多媒体教学手段进行教学, 并安排学生在 培训基地对汽车零部件进行实际拆装。对汽车进行检测与 维修, 为切实培养学生的实践技能和工作能力, 不仅要求 配备齐全的培训设备, 而且要求做到开放性, 这样可以为 学生提供更多的实践机会, 以保证每一位学生能亲手反复 操作, 巩固和运用所学知识, 提高操作技能, 积累解决实 际问题的经验。

\section{4 加强师资队伍建设}

教师在人才培养中起主导作用 ${ }^{[2]}$, 教师素质直接影响人 才培养的质量。培养高素质的汽车服务工程类专业人才, 对教师自身素质提出了更高的要求。教师不仅要具有宽厚 的行业基础理论知识和实践能力, 还必须具备将行业知识 及实践能力融于教育教学过程的能力。但在实际教学中有 不少教师虽有扎实的理论基础，却缺乏实践能力和技能。 因此, 加大对教师实践能力和技能的培训力度, 建设一支 符合培养应用型人才需求的师资队伍是提高教学质量的关 键。培养应用型人才必须要有一批应用型教师。建立应用 型师资队伍主要有以下途径: 一是从社会上汽车各企业引 进高级技术人才。这些高级技术人才具有丰富的汽车实践 经验, 熟知社会对人才能力的具体要求, 可为更好地制定 培养计划提供实践依据。二是选送教师到社会兼职或企业 培训, 以培养教师的实践能力。三是采取灵活多样的用人 方式, 由社会技术人员兼职, 开设一些实践性较强的选修 课程。四是培养 “双师型” 教师, 鼓励现有教师, 特别是 青年教师努力成为 “双师型” 教师。

\section{5 学历教育与职业培训相结合}

目前, 汽车工程学院采用本科学历教育 ${ }^{[3]}$, 即四年取得 相应学分后, 便可以获得毕业证书和本科学位证书, 但用 人单位普遍注重应聘者的职业能力和相应的职业资格证 书。因此, 在学历教育的同时, 应鼓励学生考取一个或几 
个与本专业相近的职业资格证书, 如我们现在已经具备的 职业考试资格的汽车中、高级维修工, 汽车中、高级电工 的技能培训, 以及二手车评估等等以提高学生的技术应用 能力和就业竞争力。

\section{4. 改革方案实施方法}

4.1 以应用型本科教学为定位, 为汽车市场培养高级技术人 才

应用型本科的教学理念, 即培养出来的学生应该是市 场需要的、有扎实的理论基础并兼有汽车实用技能的专门 人材, 比普通本科培养教育增加了应用技能的培养。基于 上述的教学指导思想在课程设置上没有照搬一般普通本科 院校教学计划, 而是以 “足够理论+应用技能+校外实习” 为 主旨构建课程和教学内容体系, 面向汽车后市场培养服务 型人才。在教学模式设计时, 专业课程教学采用 “理论+实 践” 的模块教学方式。如对于 “汽车服务工程” 本科专业, 在学好专业基础课程外, 还学习相关汽车后市场服务课程 《汽车维修与检测》、《汽车评估》、《现代汽车营销》、《汽 车保险与理赔》等, 这些课程都是应用型很强的课程, 对 汽车后市场人才培养非常有帮助。

\section{2 以就业为导向, 做好教学模式改革}

我们研究了国际上现代职业教育的经验和发展趋势, 在德国, 澳大利亚及香港等地区职业性专业教学都采用模块 教学法, 所谓模块教学就是将专业性较强教学课程采用 “理 论+现场+实践” 的教学方式。模块教学要达到两个基本目 的, 不但要让学生学懂理论知识, 还要学到应会的操作技 能。我们将整个教学内容按教学认知规律和汽车结构内容 划分为若干个教学模块。教师根据教学计划和模块要求自 编适合独立学院应用型人才培养的教材。在教学方法上我 们采取了四种方式:

1、实物教学和多媒体教学相结合

为了使教学过程更具有直观性, 便于学生理解和记忆, 提高学生学习兴趣。各教学模块拟采用多媒体与实物同时 进行教学。

\section{2、利用网络平台进行教学}

在汽车技术实训中心设有汽车展示实验室、液压与气 压传动实验室、汽车结构实验室

等九个实训室外, 还有一条先进的汽车检测线, 实验 室设有中心机房, 配有多媒体虚拟教学

软件, 通过动画形式完成汽车常规的结构与原理教学, 还能虚拟汽车各大总成及各部件的拆

装, 检测与维修等实践操作的教学。

\section{3、“手把手” 的教学方式}

模块教学的特点是 “零” 距离手把手教学方式, 学生 以小组为单位, 教师按生产或服务流程组织教学, 学生经 过相应理论知识培训后, 先由教师示范操作, 然后学生在 教师指导下完成操作。

4、以模块实训教学为中心, 培养 “双师型” 教师队伍 以往专业教师一般分为理论教师与实训教师。模块教 学模式注重以就业为导向的理念。

要求通过教学, 培养学生良好的职业技能和习惯, 使 学生能适应职场需求。这需要既能精通

教学理论, 又能熟练操作机器设备的 “双师型” 教师。

5、以与企业 “零” 距离接轨, 大力开展校外实习基地 的建设

为了提高学生的实践能力, 汽车工程系利用各种渠道, 与广东省一些汽车企业进行沟通与合作, 为本专业学生找 到了校外实习的岗位。将训教学与生产实际相结合, 由中 级工训练, 高级工训练, 技师培训和行业实习四个环节组 成。通过中、高级工技能训练, 使学生系统掌握现代汽车 的结构、原理、应用及检测维修等理论, 掌握汽车故障诊 断与维修等操作技能。通过技师培训, 使学生具有较高的 现代汽车技术理论知识, 及时掌握汽车新技术的发展动态, 熟练掌握汽车故障诊断与维修等操作技能, 具有一定的科 研和创新能力。

6、以与企业 “零” 距离接轨, 大力开展校外实习基地 的建设

为了提高学生的实践能力, 汽车工程系利用各种渠道, 与广东省一些汽车企业进行沟通与合作, 为本专业学生找 到了校外实习的岗位。将训教学与生产实际相结合, 由中 级工训练, 高级工训练, 技师培训和行业实习四个环节组 成。通过中、高级工技能训练, 使学生系统掌握现代汽车 的结构、原理、应用及检测维修等理论, 掌握汽车故障诊 断与维修等操作技能。通过技师培训, 使学生具有较高的 现代汽车技术理论知识, 及时掌握汽车新技术的发展动态, 熟练掌握汽车故障诊断与维修等操作技能, 具有一定的科 研和创新能力。

\section{3 对实践性教学内容进行改革}

（1）改革实践教学内容, 增加现代汽车新技术实践教 学内容

在学院已有的实践教学环境的基础上, 配置多媒体教 学系统、发动机试验系统、发动机及其整车排故系统、汽 车及其零部件总成陈列结构、整车动态演示、电控模拟示 教系统、全套汽车维修技术数据库等能让学生尽快掌握汽 车高新技术的软硬件设施。 
(2) 不断更新实践性教学内容

增添新的实践性教学内容 ${ }^{[4]}$, 淘汰旧内容, 且新技术、 新工艺、新设备、新材料在教学过程的引入, 提升了实践 内容的档次, 在同行业中保持了设备、实践内容及教学方 法的先进性。既有利于学生掌握现代汽车技术, 显著提高 了操作能力, 激发了学生对专业课的学习兴趣, 培养了学 生创新能力。

\section{4 改进实践教学方法与手段}

改进实践教学方法, 实施因材施教。过去的实践教学 基本上是以灌输式为主, 不能激发学生学习的主动性, 不 利于培养学生的创新思维和创新能力, 且实践教学教材老 化, 不系统, 针对上述不足我们在教学方法上采取了四项 改革措施。一是根据汽车新技术发展现状, 编制适合学生 创新思维、创新能力的各课程的实验指导书和相应工种的 实践教材, 所编制的实践教材注重动手能力, 操作技能及 创新能力的培养, 且标准高于国家标准。其次是开设自选 实验, 学生根据自己的爱好选择实验项目, 并拟出实验方 案, 不同程度的学生、选取实验内容难度不同, 学生量力 选题, 教师因材施教。

\section{5. 培养模式改革取得成果}

汽车服务工程人才培养模式改革方案经过几年的实 施, 在实施过程中不断通过学生的反馈调整实施方案, 取 得了一系列成果。
1、教学模式改革加强了教学过程中理论与实践相结 合, 突出了学生的实践动手能力的提升。

2、实现了校企合作、互利, 共同培养了社会需求的汽 车服务工程应用型人才。

3、通过培养模式的改革, 建立起了一只强大的 “双师 型” 教师队伍。

汽车服务工程自开设以来, 共有 500 余名毕业生, 毕 业生通过在校的一系列专业课程的学习, 在工作岗位上表 现突出, 深受用人单位好评, 尤其是动手能力突出, 不少 毕业生经过两三年的锻炼已成为生产单位技术骨干或走上 领导岗位。

\section{参考文献 (References)}

[1] Nie Guihua, Dang Linjie, "Research the professional training of automobile service engineering" Auto Industry Research., 2007, (09).

[2] Tu Qunfeng, "The Background and Education Approach of the Auto Applicationand Maintenance Major" Journal of Zhejiang Vocational and Technical Institute of Transportation. 2004.01.012.

[3] Xu Xiaoming, Zhang Xiangwei, "Research on building and Operational mechanism of comprehensive and opening experiment teaching system", Experimental Technology and Management,. 2007.07.006.

[4] Hong Lin, "The Practice Teaching System and Its Basement Construction of Applied Universities Abroad", Research and Exploration in Laboratory, 2006, (12). 1006-7167. 